\title{
Association of lower extremity range of motion and muscle strength with physical performance of community-dwelling older women
}

Hungu Jung ${ }^{*}$ and Masahiro Yamasaki

\begin{abstract}
Background: Reduced lower extremity range of motion (ROM) and muscle strength are related to functional disability in older adults who cannot perform one or more activities of daily living (ADL) independently. The purpose of this study was to determine which factors of seven lower extremity ROMs and two muscle strengths play dominant roles in the physical performance of community-dwelling older women.

Methods: Ninety-five community-dwelling older women (mean age \pm SD, $70.7 \pm 4.7$ years; age range, 65-83 years) were enrolled in this study. Seven lower extremity ROMs (hip flexion, hip extension, knee flexion, internal and external hip rotation, ankle dorsiflexion, and ankle plantar flexion) and two muscle strengths (knee extension and flexion) were measured. Physical performance tests, including functional reach test (FRT), $5 \mathrm{~m}$ gait test, four square step test (FSST), timed up and go test (TUGT), and five times sit-to-stand test (FTSST) were performed.

Results: Stepwise regression models for each of the physical performance tests revealed that hip extension ROM and knee flexion strength were important explanatory variables for FRT, FSST, and FTSST. Furthermore, ankle plantar flexion ROM and knee extension strength were significant explanatory variables for the $5 \mathrm{~m}$ gait test and TUGT. However, ankle dorsiflexion ROM was a significant explanatory variable for FRT alone. The amount of variance on stepwise multiple regression for the five physical performance tests ranged from 25 (FSST) to 47\% (TUGT).

Conclusions: Hip extension, ankle dorsiflexion, and ankle plantar flexion ROMs, as well as knee extension and flexion strengths may play primary roles in the physical performance of community-dwelling older women. Further studies should assess whether specific intervention programs targeting older women may achieve improvements in lower extremity ROM and muscle strength, and thereby play an important role in the prevention of dependence on daily activities and loss of physical function, particularly focusing on hip extension, ankle dorsiflexion, and ankle plantar flexion ROMs as well as knee extension and flexion strength.
\end{abstract}

Keywords: Elderly, Lower extremity, Muscle strength, Performance, Range of motion

\footnotetext{
* Correspondence: harazu_21@yahoo.co.jp

Graduate School of Integrated Arts and Sciences, Hiroshima University, 1-7-1

Kagamiyama, Higashi-hiroshima City, Hiroshima 739-8521, Japan
} 


\section{Background}

A previous study [1] involving 6000 participants (aged 5-92 years) showed age-related losses in range of motion (ROM) measurements obtained from seven major joints. Lower extremity ROM is an important predictor of physical function in older adults living in assisted-living housing or skilled nursing facilities [2]. Moreover, decrease in ankle dorsiflexion ROM is significantly smaller in older adults who have suffered a fall than in those who have not [3]. Therefore, the reduction in ROM that occurs with increasing age possibly plays an important role in physical function.

A decline in muscle strength is an important factor impacting the physical function of older adults. Brach and VanSwearingen [4] studied older men who had difficulty managing their activities of daily living (ADL) and found a significant relationship between physical performance test and grip force. A longitudinal study over 2.5 years found that lower quadricep muscle strength was associated with an increased risk of incidents related to mobility limitations in 3075 older adults aged 70-79 years [5]. Moreover, lower knee extension strength in older adults is related to difficulty and disability in performing ADL, such as walking indoors or outdoors [6]. Muscle weakness is associated with poor functional performance and self-reported disability [7].

Performance evaluations have been used to detect functional disability in older adults. The timed up and go test (TUGT) predicts the ability of frail older adults to go out independently [8]. The $5 \mathrm{~m}$ gait test, functional reach test (FRT), and five times sit-to-stand test (FTSST) were able to detect mobility limitations in communitydwelling older women, particularly the ability to walk $1 / 4$ mile or climb 10 steps [9]. Furthermore, the four square step test (FSST) was able to differentiate between older adult fallers and non-fallers [10]. Lower extremity performance is related to mobility because mobility difficulties occurring in older adults progress to physical disabilities, whereby they cannot practice ADL independently without assistance [11].

Although women have a consistently larger ROM than men in the same age range $[1,12]$, age-related decline in ROM is greater in women [13]. In addition, muscle strength is generally weaker in women. In previous studies, hip flexion $[2,14,15]$, knee flexion $[2,14,15]$, ankle dorsiflexion $[2,14,16]$, and ankle plantar flexion ROMs $[2,14,16]$ were found to be significantly associated with physical performance, but those studies did not consider hip extension or internal and external hip rotation ROMs. On the other hand, strong knee extension and flexion strength are associated with the maintenance of balance on walking [17]. Although ROM and muscle strength are considered to be important factors that influence physical performance, little information is available on the extent to which each ROM and muscle strength value is associated with the physical performance of community-dwelling older women.

Therefore, the purpose of this study was to determine which of the seven lower extremity ROMs (hip flexion, hip extension, knee flexion, internal and external hip rotations, and ankle dorsiflexion and ankle plantar flexion) and two muscle strengths (knee extension and flexion) play dominant roles in the physical performance of community-dwelling older women.

\section{Methods}

This study was a cross-sectional observational study. Participants were recruited with the assistance of public learning facilities through various channels, including local newspapers, posters, fliers, senior newsletters, visits to tea parties, activities to explain the purpose of the study, and educational seminars regarding physical function, fall prevention, and senior exercise.

The eligibility criteria were as follows: age $\geq 65$ years, living independently in the community, and no serious neurological, musculoskeletal, cognitive, visual, or sensory disorders which would affect their ADL. Individuals who could not perform the physical performance tests or ADL without assistance were excluded from the study. Participants were recruited in Hiroshima, Japan from July 2013 to October 2015. Prior to the beginning of testing, we explained to the participants the purpose and procedures of the study and all participants provided written informed consent. The Ethical Committee of the Graduate School of Integrated Arts and Science of Hiroshima University approved this study (ID: 25-26).

\section{Procedures}

All measurements and self-report questionnaires were conducted in local community centers for ease of accessibility. The five physical performance tests were conducted by either five examiners who took charge of each of the five tests, or by the principal investigator. The five examiners had 2 years of experience in the five physical performance tests and, therefore, were familiar with them. The principal investigator had 5 years of experience in ROM and muscle strength measurements as well as in the five physical performance tests. The participants were instructed that when a test was finished in a section, they should move to another section to be measured for the next test. The participants were able to take a short break between tests. After the physical performance tests, the participants were asked to fill in self-report questionnaires. All self-report questionnaires were checked during face-to-face interviews.

Measurements of ROM and muscle strength were performed on participants 1 week after the physical 
performance tests. Measurements were taken by the principal investigator with a research assistant; one assisted the participant with the measurement of muscle strength and the other recorded the results. Muscle strength measurements were taken, followed by a $5 \mathrm{~min}$ rest, followed by ROM.

\section{Self-report questionnaires}

Age, sex, illness, smoking status, drinking status, pain, and perceived health data were obtained through self-report questionnaires. Body height was measured in centimeters using a vertical standard wall tape. Body mass was measured in kilograms using a calibrated digital scale.

Regarding pain, participants were asked about the presence/absence of pain in the first question, "Have you had any pain in your body during the past 1 month?" Individuals with pain were asked to mark the location of their pain on the McGill pain map (MPM) [18]. The MPM consists of anterior and posterior figures of the body, divided into 36 numbered anatomic regions. The validity and reliability of the MPM have been demonstrated in previous studies $[18,19]$. We investigated pain of the lower extremities, including the lower back, sacrum, hips, buttocks, thighs, knees, legs, ankles, and feet, because we believed that lower extremity pain would affect physical performance. The next question asked was as follows, "Does the pain disturb your daily life activities?" We categorized the lower extremity level of pain as follows: no pain $=0$, hardly ever $=1$, occasionally $=2$, sometimes $=3$, frequently $=4$, and almost always $=5$.

\section{Lower extremity range of motion}

Active ROM was measured using the method specified by Norkin and White [20]. The same principal investigator performed bilateral measurements using a standard goniometer for all lower extremity ROMs to maximize the consistency of the measurement results [15]. In a previous study [21], ROM was measured using the same goniometer by the same examiner for optimal reliability (ICC: $0.80-0.96)$. Prior to measuring, the participants were not allowed to warm up their body as this may have affected the results. There was a $1 \mathrm{~min}$ rest after the measurements were taken in each position. To measure active ROMs, the participants were asked to move the full range of joint motion at a comfortable speed by themselves. Hip extension and knee flexion ROMs were obtained with participants placed in the prone position. Internal and external hip rotation ROMs and ankle dorsiflexion and plantar flexion ROMs were recorded with participants seated on a tall chair with their feet off the floor and knee flexed to $90^{\circ}$. Hip flexion ROM was obtained with participants in the supine position. All ROMs were measured once, and the mean values of the left and right sides of each motion were used for analysis.

\section{Lower extremity muscle strength}

In this study, knee extension and flexion strength measurements were selected based on a previous study [22], which reported that knee strength can be used to characterize overall lower extremity muscle strength. These variables were measured bilaterally by the same principal investigator using a dynamometer (HDD $\mu$ TasF-1, Anima Corp., Tokyo, Japan). Excellent reliability for muscle strength measurements (ICC: 0.75-0.97) using the same type of dynamometer has previously been reported [23]. The dynamometer was calibrated in a factory prior to measurements. The participants were seated in a constructed chair and were secured by seat belts around his or her body and thigh. Two structures were installed between the chair front legs and between the chair back legs. During the measurements of isometric muscle strength, the dynamometer sensor was fastened to the ankle with Velcro tape, with the trunk and thigh stabilized, while the anchor belt was fixed to an available structure to directly oppose the knee extension and flexion movements. The maximal muscle strength over a $5 \mathrm{~s}$ time period was recorded twice and measured in Newtons. There was a 1 min rest between the two trials. The mean values of the two trials on the right and left were used for analysis.

\section{Physical performance tests}

For FRT [24], the participant stood with his/her feet shoulder-width apart and with his/her right arm raised from $90^{\circ}$ of flexion along a yardstick placed at the shoulder level and was then asked to reach as far forward as possible, while both feet stayed on the ground to maintain balance. The distance reached was measured in centimeters.

The $5 \mathrm{~m}$ gait test [25] was measured as the time taken to walk an $11 \mathrm{~m}$ straight line from the first step past the $3 \mathrm{~m}$ mark to the first step past the $8 \mathrm{~m}$ mark at a comfortable speed.

FSST was performed as previously described [10]. Four squares were placed like a cross on the floor with the tips of four canes facing each other. Canes were approximately $2.5-\mathrm{cm}$-high and $90-\mathrm{cm}$-long. The aim of the FSST was to step as fast as possible into each square as follows: the participant stood in square number 1 , the test began when the participant stepped forward into square number 2 . The participant then stepped clockwise, from square 2 to square 3 moving sideways, backwards to square 4 , returning to square 1 moving sideways. Then, stepping counterclockwise, sideways to square 4 , forwards to square 3 , sideways to square 2 , and backwards in square 1 with both feet. The test ended when the participant completed the sequence. The total time taken for FSST was measured.

TUGT [8], modified from an original study, was used in this study. We instructed the participants to rise from 
an armless chair with a seat height of $43 \mathrm{~cm}$, walk $3 \mathrm{~m}$ forward, turn around, return, and sit down. The participants performed TUGT at their usual pace. Timing was calculated from when the participant rose from the initial sitting position at the go command to return to sit down.

FTSST [26] was measured as the time taken to stand up and sit down as fast as possible five times from an armless 43-cm-high chair. The test began when the participant stood up from the initial sitting position at the go command and ended when the participant was in the final fully upright position at the end of the fifth stand.

All physical performance tests used in this study involved one practice trial prior to two trial measurements, with a $1 \mathrm{~min}$ rest between the two trials. The results of the $5 \mathrm{~m}$ gait test, FSST, and FTSST were recorded using a digital stopwatch. Mean values of the two trials were used for further analysis. The FRT [24], $5 \mathrm{~m}$ gait test [25], FSST [10], TUGT [8], and FTSST [26] are reliable and valid measures and have previously been reported in the literature.

\section{Statistical analysis}

Pearson correlation coefficients were used to calculate correlations among study variables. Principal component analysis (PCA) was used to identify covariation patterns among seven lower extremity ROMs. To assess the influence of age, BMI, pain, and lower extremity ROM and muscle strength on physical performance, stepwise multiple regression analyses were constructed using the physical performance measures as the dependent variables. Since the five dependent variables were significantly correlated $(r=-0.30-0.80 ; p<0.01)$, a Bonferroni adjustment at a significance level of $0.01(0.05 / 5)$ was used. All data analysis was undertaken on a personal computer using SPSS (version 18, SPSS, JAPAN).

\section{Results}

Characteristics of the 95 participants are shown in Table 1. Apart from 24 participants without pain, most participants had some degree of pain, which disturbed their activities of daily life. Eleven participants were frequently or almost always disturbed by pain.

Table 2 shows the illness status, smoking status, and drinking status of participants. Hypertension and arthritis were the most common chronic diseases. Table 3 shows the descriptive statistics for each of the physical performance test measures, the ROMs, and muscle strength measures.

Pearson correlations between physical performance test scores and participant characteristics are shown in Table 4. Age and pain were significantly associated
Table 1 Physical characteristics, pain, and perceived health of study population $(n=95)$

\begin{tabular}{lr}
\hline Variables & Mean $\pm \mathrm{SD}$ \\
\hline Age (years) & $70.7 \pm 4.7$ \\
Height $(\mathrm{cm})$ & $152.4 \pm 5.0$ \\
Mass $(\mathrm{kg})$ & $53.2 \pm 6.9$ \\
BMI $\left(\mathrm{kg} / \mathrm{m}^{2}\right)$ & $23.0 \pm 3.0$ \\
Pain $^{\mathrm{a}}$ & $1.8 \pm 1.4$ \\
Perceived health (1 poor $~_{\text {4very good) }}$ & $2.9 \pm 0.5$
\end{tabular}

${ }^{a}$ No pain $=0$. Responses of the subject with pain to the question "Does the pain disturb your daily life activities?" were ranked as follows; hardly ever $=1$, occasionally $=2$, sometimes $=3$, frequently $=4$, and almost always $=5$

with all physical performance test scores $(r=0.23-$ $0.34 ; p<0.05)$.

Table 5 shows the pairwise Pearson correlations among ROMs and muscle strengths. Most of the ROMs and muscle strengths were significantly associated with each other $(r=0.20-0.70 ; p<0.05)$. The association between hip extension ROM and knee flexion strength was moderate $(r=0.42 ; p<0.001)$.

PCA extracted only one principal component for ROMs, which explains $40.7 \%$ of the variance (eigenvalue $=2.854) \quad($ Fig. 1). Extremity positive values of loadings were observed for all ROMs.

Table 2 Illness, smoking, and drinking status

\begin{tabular}{ll}
\hline Variables & $n(\%)$ \\
\hline IIness & \\
Cerebrovascular disease & $4(4.2)$ \\
Hypertension & $30(31.6)$ \\
Osteoporosis & $17(17.9)$ \\
Cardiac disease & $9(9.5)$ \\
Diabetes & $10(10.5)$ \\
Arthritis & $30(31.6)$ \\
Pulmonary disease & $2(2.1)$ \\
Cancer & $9(9.5)$ \\
No illness & $29(30.5)$ \\
1 illness & $29(30.5)$ \\
2 illnesses & $23(24.2)$ \\
3 illnesses & $11(11.6)$ \\
4 more than illnesses & $3(3.3)$ \\
Smoking & \\
Current smoker & $1(1.1)$ \\
Non-smoker & $94(98.9)$ \\
Drinking & $18(18.9)$ \\
Current drinker & $77(81.1)$ \\
Non-drinker &
\end{tabular}


Table 3 Mean values of physical performance tests, range of motion, and muscle strength

\begin{tabular}{lll}
\hline Variables & Mean \pm SD & Minimum - maximum \\
\hline Physical performance tests & & \\
Functional reach Test (cm) & $30.1 \pm 4.9$ & $18-45$ \\
5 m gait test (s) & $3.3 \pm 0.7$ & $2.5-6.9$ \\
Four square step test (s) & $6.7 \pm 1.8$ & $4.3-17.0$ \\
Timed up and go test (s) & $6.9 \pm 1.5$ & $4.6-15.7$ \\
Five times sit-to-stand test (s) & $7.5 \pm 2.0$ & $4.3-14.7$ \\
Range of motion (degree) & & \\
Hip flexion & $122.6 \pm 10.8$ & $53-144$ \\
Hip extension & $16.8 \pm 4.5$ & $8-27$ \\
Knee flexion & $127.6 \pm 8.3$ & $104-144$ \\
Hip internal rotation & $27.9 \pm 6.1$ & $14-47$ \\
Hip external rotation & $28.5 \pm 4.9$ & $17-42$ \\
Ankle dorsiflexion & $17.7 \pm 6.0$ & $5-31$ \\
Ankle plantar flexion & $58.0 \pm 7.9$ & $28-74$ \\
Muscle strength (N) & & \\
Knee extension strength & $174.1 \pm 53.3$ & $71.8-339.5$ \\
Knee flexion strength & $80.2 \pm 27.7$ & $27.0-164.5$ \\
\hline
\end{tabular}

Table 6 presents the Pearson correlations of ROM and muscle strength with physical performance test scores. Most ROM and muscle strength variables were consistently associated with physical performance test scores $(r=-0.21-0.56 ; p<0.05)$, particularly hip extension ROM and both types of knee strength which showed a moderate correlation with physical performance test scores $(r=0.30-0.56 ; p<0.01)$. However, ankle dorsiflexion ROM did not significantly correlate with the $5 \mathrm{~m}$ gait test or TUGT.

The results of the stepwise multiple regression analyses for each of the physical performance tests are presented in Table 7. Age, BMI, pain, and all lower extremity ROM and muscle strength variables were included in the forward, stepwise conditional regression analyses. Hip extension ROM and knee flexion strength were found to be important explanatory variables for FRT, FSST, and FTSST. In addition, ankle plantar flexion ROM and knee extension strength were significant explanatory variables for the $5 \mathrm{~m}$ gait test and TUGT. However, ankle dorsiflexion ROM was a significant explanatory variable for FRT alone. The amount of variance on stepwise multiple regression for the five physical performance tests ranged from 25 (FSST) to 47\% (TUGT).

\section{Discussion}

We demonstrated that lower extremity ROM and muscle strength were significantly associated with lower extremity physical performance test scores in community-dwelling older women. Only one principal component was extracted by PCA using seven lower extremity ROMs, and most of the lower extremity ROMs were significantly correlated with each other. These results may indicate that lower extremity ROMs, as a whole, were associated with the physical performance of community-dwelling older women. Beissner et al. [2] investigated the relationship between physical performance and ADL and concluded that to maintain the ability to perform ADL, ROM, and muscle strength should be increased in older adults. They also indicated that lower extremity ROM and muscle strength are predictors of functional disability in older adults living in assisted living houses who cannot independently perform for one or more ADL. Consistent with these findings, our results also emphasize the important relationship between lower extremity ROM and muscle strength and physical performance.

We found that hip extension ROM and knee flexion strength were significant explanatory variables for FRT, FSST, and FTSST. It has been reported that restricted hip extension ROM is related to reduced stability of the lumbopelvic region [27], characterized by poor control during a static stabilization task and hip movement while ascending and descending a flight of stairs [28]. Knee flexion strength was poor in participants who had suffered falls because of reduced static and dynamic balance capability [29]. Our results suggested that hip

Table 4 Pearson correlations between physical performance test scores and participant characteristics

\begin{tabular}{|c|c|c|c|c|c|c|c|c|c|c|}
\hline \multirow[t]{2}{*}{ Characteristic } & \multicolumn{2}{|c|}{ Functional reach test } & \multicolumn{2}{|c|}{$5 \mathrm{~m}$ gait test } & \multicolumn{2}{|c|}{ Four square step test } & \multicolumn{2}{|c|}{ Timed up and go test } & \multicolumn{2}{|c|}{ Five times sit-to-stand test } \\
\hline & $r$ & $p$ value & $r$ & $p$ value & $r$ & $p$ value & $r$ & $p$ value & $r$ & $p$ value \\
\hline$\overline{\text { Age }}$ & -0.19 & 0.063 & $0.34^{\mathrm{b}}$ & $<0.001$ & $0.23^{\mathrm{a}}$ & 0.024 & $0.36^{\mathrm{b}}$ & $<0.001$ & $0.24^{\mathrm{a}}$ & 0.020 \\
\hline Height & $0.32^{b}$ & 0.002 & -0.18 & 0.074 & -0.01 & 0.891 & -0.20 & 0.052 & 0.03 & 0.785 \\
\hline Body mass & -0.18 & 0.076 & 0.11 & 0.292 & 0.08 & 0.434 & 0.08 & 0.442 & 0.19 & 0.060 \\
\hline BMI & $-0.34^{b}$ & $<0.001$ & 0.20 & 0.053 & 0.08 & 0.439 & 0.18 & 0.081 & 0.18 & 0.085 \\
\hline Pain & $-0.25^{\mathrm{a}}$ & 0.014 & $0.23^{\mathrm{a}}$ & 0.027 & $0.31^{b}$ & 0.002 & $0.22^{\mathrm{a}}$ & 0.034 & $0.26^{\mathrm{a}}$ & 0.012 \\
\hline
\end{tabular}

${ }^{a} p<0.05$

$\mathrm{b}_{p}<0.01$
0.05 


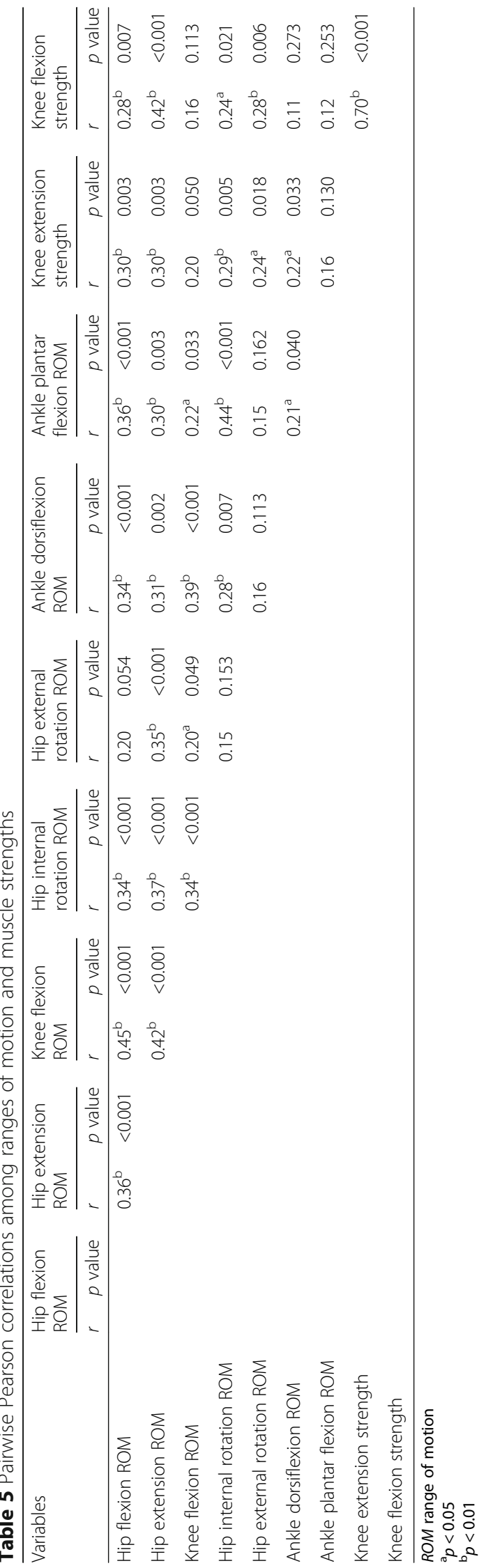


Principal Componet $(40.7 \%)$

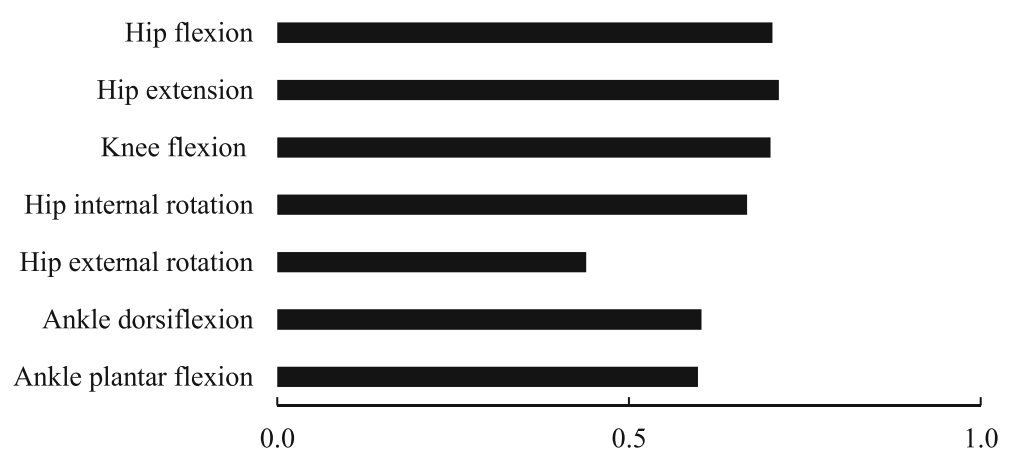

Fig. 1 Factor loadings of principal component

extension ROM and knee flexion strength influence the movements that are required for performing FRT, FSST, and FTSST.

Ankle plantar flexion ROM and knee extension strength were significant determinants of $5 \mathrm{~m}$ gait test and TUGT scores. Ankle ROM with reduction in both plantar flexion and dorsiflexion was found to be relevant when performing the figure of 8 walking test (F8WT) [30]. TUGT and F8WT involve similar movements, whereby the participant is required to turn around a cone placed at a distance of approximately $5 \mathrm{ft}$. Here, ankle plantar flexion ROM was strongly associated with TUGT rather than ankle dorsiflexion ROM. It is likely that ankle plantar flexion ROM largely influences movements during the TUGT compared with ankle dorsiflexion ROM. In addition, these findings are consistent with those of a previous study [31], which reported that knee extension strength was a significant predictor of walking speed. Reduced knee extension strength over a period of
2.5 years in older people was associated with difficulties in walking $1 / 4$ mile without resting [5]. Therefore, it is possible that ankle plantar flexion ROM and knee extension strength are associated with mobility.

Ankle dorsiflexion ROM was a significant explanatory variable only for FRT. A strong association exists between ankle dorsiflexion ROM and FRT in communitydwelling older women [16]. Moreover, ankle dorsiflexion $\mathrm{ROM}$ is associated with leaning balance as measured using the maximal balance test in a standing position [31]. These results may indicate that ankle dorsiflexion ROM contributes to the maintenance of an upright posture during forward-reaching tasks.

Our study had several limitations. It is clear that the strength of the associations was relatively modest and that much of the variance in the physical performance tests remained unaccounted for. This may be because our study participants had a high level of perceived health, and there was a relatively weak correlation

Table 6 Pearson correlations of range of motion and muscle strength with physical performance test scores

\begin{tabular}{|c|c|c|c|c|c|c|c|c|c|c|}
\hline \multirow[t]{2}{*}{ Variables } & \multicolumn{2}{|c|}{ Functional reach test } & \multicolumn{2}{|c|}{$5 \mathrm{~m}$ gait test } & \multicolumn{2}{|c|}{ Four square step test } & \multicolumn{2}{|c|}{ Timed up and go test } & \multicolumn{2}{|c|}{ Five times sit-to-stand test } \\
\hline & $r$ & $p$ value & $r$ & $p$ value & $r$ & $p$ value & $r$ & $p$ value & $r$ & $p$ value \\
\hline Hip flexion ROM & $0.32^{b}$ & 0.002 & $-0.29^{b}$ & 0.003 & -0.20 & 0.053 & $-0.32^{b}$ & 0.002 & $-0.26^{\mathrm{a}}$ & 0.013 \\
\hline Hip extension ROM & $0.56^{\mathrm{b}}$ & $<0.001$ & $-0.33^{b}$ & 0.001 & $-0.41^{b}$ & $<0.001$ & $-0.35^{b}$ & $<0.001$ & $-0.46^{\mathrm{b}}$ & $<0.001$ \\
\hline Knee flexion ROM & $0.45^{b}$ & $<0.001$ & $-0.27^{b}$ & 0.009 & $-0.30^{\mathrm{b}}$ & 0.003 & $-0.25^{\mathrm{a}}$ & 0.013 & -0.20 & 0.056 \\
\hline Hip internal rotation ROM & $0.25^{\mathrm{a}}$ & 0.014 & $-0.32^{\mathrm{b}}$ & 0.001 & $-0.25^{\mathrm{a}}$ & 0.013 & $-0.38^{b}$ & $<0.001$ & $-0.34^{\mathrm{b}}$ & $<0.001$ \\
\hline Hip external rotation ROM & $0.38^{\mathrm{b}}$ & $<0.001$ & $-0.24^{\mathrm{a}}$ & 0.020 & -0.19 & 0.060 & -0.14 & 0.177 & $-0.28^{b}$ & 0.006 \\
\hline Ankle dorsiflexion ROM & $0.45^{\mathrm{b}}$ & $<0.001$ & -0.16 & 0.110 & $-0.21^{\mathrm{a}}$ & 0.040 & $-0.21^{\mathrm{a}}$ & 0.047 & -0.18 & 0.080 \\
\hline Ankle plantar flexion ROM & $0.28^{b}$ & 0.006 & $-0.38^{\mathrm{b}}$ & $<0.001$ & -0.17 & 0.101 & $-0.51^{b}$ & $<0.001$ & $-0.29^{b}$ & 0.004 \\
\hline Knee extension strength & $0.30^{\mathrm{b}}$ & 0.003 & $-0.47^{b}$ & $<0.001$ & $-0.42^{b}$ & $<0.001$ & $-0.50^{b}$ & $<0.001$ & $-0.42^{\mathrm{b}}$ & $<0.001$ \\
\hline Knee flexion strength & $0.43^{b}$ & $<0.001$ & $-0.42^{\mathrm{b}}$ & $<0.001$ & $-0.45^{b}$ & $<0.001$ & $-0.41^{b}$ & $<0.001$ & $-0.48^{\mathrm{b}}$ & $<0.001$ \\
\hline
\end{tabular}

$R O M$ range of motion

${ }^{\mathrm{a}} p<0.05$

${ }^{\mathrm{b}} p<0.01$ 
Table 7 Stepwise multiple regression analyses using physical performance test scores

\begin{tabular}{|c|c|c|c|c|c|c|c|c|}
\hline Item & Explanatory variable & B & SE & Standardized $\beta$ & $t$ & $p$ value & Adjusted $R^{2}$ & $F$ \\
\hline \multirow[t]{3}{*}{ Functional reach test } & Hip extension ROM & 0.32 & 0.10 & 0.30 & 3.16 & 0.002 & & \\
\hline & Ankle dorsiflexion ROM & 0.21 & 0.07 & 0.26 & 3.08 & 0.003 & & \\
\hline & Knee flexion strength & 0.04 & 0.02 & 0.24 & 2.88 & 0.005 & 0.44 & 19.68 \\
\hline \multirow[t]{2}{*}{$5 \mathrm{~m}$ gait test } & Ankle plantar flexion $\mathrm{ROM}$ & -0.02 & 0.01 & -0.28 & -3.25 & 0.002 & & \\
\hline & Knee extension strength & 0.00 & 0.00 & -0.38 & -4.49 & $<0.001$ & 0.34 & 17.15 \\
\hline \multirow[t]{2}{*}{ Four square step test } & Hip extension ROM & -0.11 & 0.04 & -0.27 & -2.69 & 0.008 & & \\
\hline & Knee flexion strength & -0.02 & 0.01 & -0.34 & -3.46 & 0.001 & 0.25 & 16.41 \\
\hline \multirow[t]{3}{*}{ Timed up and go test } & Age & 0.07 & 0.03 & 0.22 & 2.87 & 0.005 & & \\
\hline & Ankle plantar flexion $\mathrm{ROM}$ & -0.08 & 0.02 & -0.41 & -5.28 & $<0.001$ & & \\
\hline & Knee extension strength & -0.01 & 0.00 & -0.40 & -5.27 & $<0.001$ & 0.47 & 29.07 \\
\hline \multirow[t]{2}{*}{ Five times sit-to-stand test } & Hip extension ROM & -0.14 & 0.04 & -0.31 & -3.27 & 0.001 & & \\
\hline & Knee flexion strength & -0.02 & 0.01 & -0.34 & -3.60 & 0.001 & 0.29 & 20.35 \\
\hline
\end{tabular}

All regression models were significant $(p<0.001)$

$R O M$ range of motion

between pain and physical performance test scores. These characteristics of the sample may have resulted in greater homogeneity than those of previous studies $[1,5]$. Furthermore, the results obtained in this study were induced by older Japanese women, and so cannot be generalized for most of the population. It is also possible that other ROM and strength variables should have been evaluated or that the measures selected were too insensitive to detect subtle but significant impairments in ROMs and muscle strength. Ankle inversion-eversion ROM and ankle dorsiflexion strength are significantly correlated with functional performance [16, 26]. However, our study did not conduct ROM and muscle strength measurements for all extremities to minimize the stress of testing on participants.

Despite these limitations, our results have potentially important implications for the physical performance of community-dwelling older women. Considering that associations between lower extremity function, disability, and mortality have been previously reported [32], further investigations on lower extremity ROM and muscle strength for the improvement of physical performance are warranted because such improvement may contribute to the physical functioning of community-dwelling older women.

\section{Conclusions}

We demonstrated that lower extremity ROM and muscle strength were associated with physical performance test results. Hip extension, ankle dorsiflexion, and ankle plantar flexion ROMs, as well as knee extension and flexion strength are important factors that influence the physical performance of community-dwelling older women. Further studies should assess whether specific intervention programs targeting older women may achieve improvements in lower extremity ROM and muscle strength, and thereby play an important role in the prevention of dependence on daily activities and loss of physical function, particularly focusing on hip extension, ankle dorsiflexion, and ankle plantar flexion ROMs as well as knee extension and flexion strength.

\section{Abbreviations}

ADL: Activities of daily living; F8WT: Figure of 8 walking test; FRT: Functional reach test; FSST: Four square step test; FTSST: Five times sit-to-stand test; MPM: McGill pain map; ROM: Range of motion; TUGT: Timed up and go test

\section{Authors' contributions}

HJ contributed to the study design, data acquisition, statistical analysis, interpretation of the results, and manuscript preparation. MY participated in the study and reviewed the manuscript. All authors read and approved the final manuscript.

\section{Completing interests}

The authors declare that they have no competing interests.

Received: 17 October 2016 Accepted: 1 December 2016

Published online: 08 December 2016

\section{References}

1. Medeiros HB, De Araújo DS, De Araújo CG. Age-related mobility loss is joint-specific: an analysis from 6,000 Flexitest results. Age (Dordr). 2013:35(6):2399-407.

2. Beissner $\mathrm{KL}$, Collins JE, Holmes $\mathrm{H}$. Muscle force and range of motion as predictors of function in older adults. Phys Ther. 2000;80(6):556-63.

3. Menz HB, Morris ME, Lord SR. Foot and ankle risk factors for falls in older people: a prospective study. J Gerontol A Biol Sci Med Sci. 2006;61(8):866-70.

4. Brach JS, VanSwearingen JM. Physical impairment and disability: relationship to performance of activities of daily living in community-dwelling older men. Phys Ther. 2002;82(8):752-61.

5. Visser M, Goodpaster BH, Kritchevsky SB, Newman AB, Nevitt M, Rubin SM, et al. Muscle mass, muscle strength, and muscle fat infiltration as predictors of incident mobility limitations in well-functioning older persons. J Gerontol A Biol Sci Med Sci. 2005:60(3):324-33.

6. Rantanen T, Era P, Heikkinen E. Maximal isometric strength and mobility among 75-year-old men and women. Age Ageing. 1994;23(2):132-7.

7. Rantanen T, Guralnik JM, Ferrucci L, Penninx BWJH, Leveille S, Sipilä S, et al. Coimpairments as predictors of severe walking disability in older women. J Am Geriatr Soc. 2001;49(1):21-7. 
8. Podsiadlo D, Richardson S. The timed "Up \& Go": a test of basic functional mobility for frail elderly persons. J Am Geriatr Soc. 1991;39(2):142-8.

9. Kim MJ, Seino S, Kim MK, Yabushita N, Okura T, Okuno J, et al. Validation of lower extremity performance tests for determining the mobility limitation levels in community-dwelling older women. Aging Clin Exp Res. 2009;21(6):437-44.

10. Dite W, Temple VA. A clinical test of stepping and change of direction to identify multiple falling older adults. Arch Phys Med Rehabil. 2002;83(11):1566-71.

11. Lan TY, Melzer D, Tom BD, Guralnik JM. Performance tests and disability: developing an objective index of mobility-related limitation in older populations. J Gerontol A Biol Sci Med Sci. 2002;57(5):M294-301.

12. Bell RD, Hoshizaki TB. Relationships of age and sex with range of motion of seventeen joint actions in humans. Can J Appl Sport Sci. 1981;6(4):202-6.

13. Vandervoort AA, Chesworth BM, Cunningham DA, Rechnitzer PA, Paterson $\mathrm{DH}$, Koval JJ. An outcome measure to quantify passive stiffness of the ankle. Can J Public Health. 1992;83 suppl 2:519-23.

14. Gerety MB, Mulrow CD, Tuley MR, Hazuda HP, Lichtenstein MJ, Bohannon R, et al. Development and validation of a physical performance instrument for the functionally impaired elderly: the Physical Disability Index (PDI). J Gerontol. 1993;48:M33-8.

15. Escalante A, Lichtenstein MJ, Hazuda HP. Walking velocity in aged persons: its association with lower extremity joint range of motion. Arthritis Rheum. 2001:45(3):287-94.

16. Mecagni C, Smith JP, Roberts KE, O'Sullivan SB. Balance and ankle range of motion in community-dwelling women aged 64 to 87 years: a correlational study. Phys Ther. 2000;80:1004-11.

17. Ding L, Yang F. Muscle weakness is related to slip-initiated falls among community-dwelling older adults. J Biomech. 2016;49:238-43.

18. Escalante A, Lichtenstein MJ, Lawrence VA, Roberson M, Hazuda HP. Where does it hurt? Stability of recordings of pain location using the McGill Pain Map. J Rheumatol. 1996;23(10):1788-93.

19. Escalante A, Lichtenstein MJ, White K, Rios N, Hazuda HP. A method for scoring the pain map of the McGill Pain Questionnaire for use in epidemiologic studies. Aging (Milano). 1995;7(5):358-66.

20. Norkin CC, White DJ. Measurement of joint motion: a guide to goniometry. 2nd ed. Philadelphia: Davis; 2011.

21. Clapper MP, Wolf SL. Comparison of the reliability of the Orthoranger and the standard goniometer for assessing active lower extremity range of motion. Phys Ther. 1988;68:214-8.

22. Bohannon RW, Magasi SR, Bubela DJ, Wang YC, Gershon RC. Grip and knee extension muscle strength reflect a common construct among adults. Muscle Nerve. 2012;46(4):555-8.

23. Katoh M, Yamasaki H. Test-retest reliability of isometric leg muscle strength measurements made using a hand-held dynamometer restrained by a belt: comparisons during and between sessions. J Phys Ther Sci. 2009;21:239-43.

24. Duncan PW, Weiner DK, Chandler J, Studenski S. Functional reach: a new clinical measure of balance. J Gerontol. 1990;45:M192-7.

25. Nagasaki H, Itoh H, Hashizume K, Furuna T, Maruyama H, Kinugasa T. Walking patterns and finger rhythm of older adults. Percept Mot Skills. 1996;82:435-47.

26. Lord SR, Murray SM, Chapman K, Munro B, Tiedemann A. Sit-to-stand performance depends on sensation, speed, balance, and psychological status in addition to strength in older people. J Gerontol A Biol Sci Med Sci. 2002;57(8):M539-43.

27. Ahrmann SA. Diagnosis and treatment of movement impairment syndromes. 1st ed. Missouri: Mosby; 2002

28. Mascal CL, Landel R, Powers C. Management of patellofemoral pain targeting hip, pelvis, and trunk muscle function: 2 case reports. J Orthop Sports Phys Ther. 2003;33(11):647-60.

29. Ozyemisci-Taskiran O, Gunendi Z, Tas N. Assessment of isokinetic knee flexor and extensor strength and balance ability in the elderly. Turk J Geriatr. 2011:14(1):1-8.

30. Odonkor CA, Thomas JC, Holt N, Latham N, VanSwearingen J, Brach JS, et al. A comparison of straight- and curved-path walking tests among mobilitylimited older adults. J Gerontol A Biol Sci Med Sci. 2013;68:1532-9.

31. Menz HB, Morris ME, Lord SR. Foot and ankle characteristics associated with impaired balance and functional ability in older people. J Gerontol A Biol Sci Med Sci. 2005;60(12):1546-52.

32. Guralnik JM, Simonsick EM, Ferrucci L, Glynn RJ, Berkman LF, Blazer DG, et al. A short physical performance battery assessing lower extremity function: association with self-reported disability and prediction of mortality and nursing home admission. J Gerontol. 1994;49:M85-94.

\section{Submit your next manuscript to BioMed Central and we will help you at every step:}

- We accept pre-submission inquiries

- Our selector tool helps you to find the most relevant journal

- We provide round the clock customer support

- Convenient online submission

- Thorough peer review

- Inclusion in PubMed and all major indexing services

- Maximum visibility for your research

Submit your manuscript at www.biomedcentral.com/submit
Biomed Central 